\title{
Research and Practice of Flipped Classroom Teaching Mode in Software Design Courses
}

\author{
Hui Yan \\ School of computer science \& engineering \\ Xi'an technological university \\ Xi'an, China \\ e-mail: hywork_sina@qq.com
}

\author{
Zhao Li \\ School of computer science \& engineering \\ Xi'an technological university \\ Xi'an, China \\ e-mail: zhaoli1998@163.com
}

\begin{abstract}
With the development of information technology, the popularity of mobile devices, through the network learning can effectively improve the students' learning efficiency in this article, through analysis of the software design courses, flip classroom pattern research, exploration to build online collaborative learning platform based on the pattern of flip classroom, to promote the students develop goals, reduce the teacher resources.
\end{abstract}

Keywords-Flipped Classroom; Software Design Courses; Continuous Improvement; Learning Platform

\section{INTRODUCTION}

With the wide application of computers in all walks of life, the need for computer talents is constantly increasing. Students' software design and software development ability are important aspects of the training of computer-related majors. Accompanied by smartphones, tablets and other mobile devices the development of college students in the new period's growing dependence to the network, information technology has brought great influence on people's learning life, especially in the "Internet +", under the tide of how to make full use of existing network condition, the optimized teaching mode is using constantly strengthen the function of teaching media to solve software design theory of curriculum knowledge is loose, and subsequent practice easy to disconnect, when students learn the effect is not ideal, is a teacher in the software design courses teaching a subject worth studying.

\section{CHARACTERISTICS OF SOFTWARE DESIGN COURSES}

Software design courses is according to the training plan for training students in software technology literacy includes many computer professional courses. It involves programming languages, databases, software development tools, system platforms, standards, design patterns, and so on. It is a basic professional knowledge of computer science, mathematics and management science. These courses on the one hand is to introduce the basic theory of software design, development, principle and method as shown in figure 1 of the operating system, data structure, database concepts, software engineering, such as senior program design course. At the same time, these courses also contain certain practical operation training, which is mostly a combination of training courses. In learning, the software design of an introductory course to understand the basic theory and basic structure of the computer, on the basis of gradually establish and use computer to solve the problems in software design and development of ideas and methods. With the progress of the curriculum system, the students' mastery and application of the algorithm can be enhanced gradually. However, in the traditional teaching process, the teaching of knowledge is done by teachers in the classroom, and the digestion of knowledge requires the students to practice their own practice through operation and homework. The classroom teacher to teach, students for the first time couldn't focus tend to ignore the details, can't remember dedicates some steps and key points, in the subsequent actual practice before and after the operation of links up, unable to realize, will affect learning interest and enthusiasm, make the learning effect. Therefore, it is necessary to improve the teaching of software design courses with appropriate teaching mode.

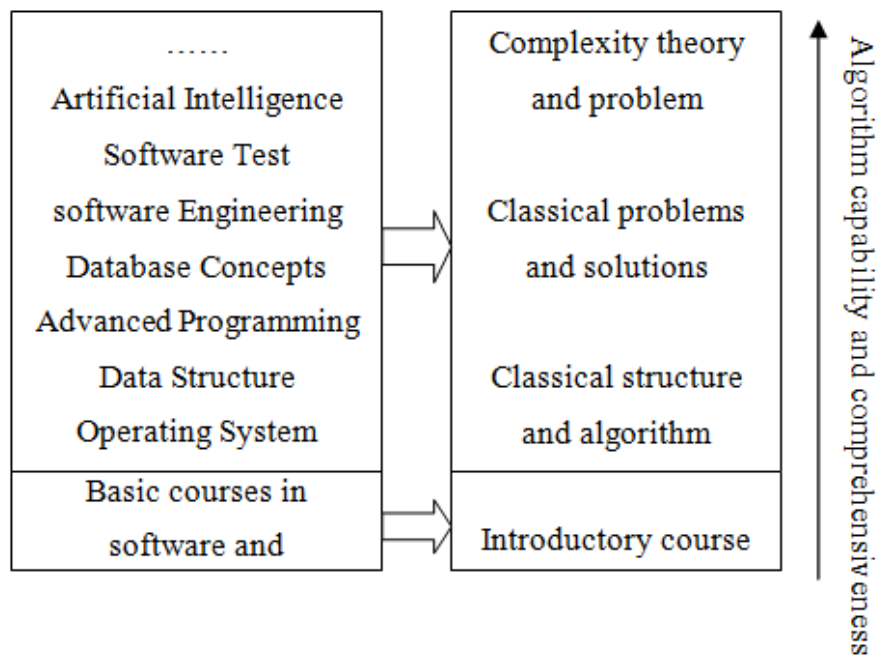

Figure 1. Class curriculum system of software design

\section{FLIPPED CLASSROOM MODE}

The flipped classroom started in 2007 when Jonathan Bergmann and Aaron Sams, a chemistry teacher at the High School in woodland park, colo., used video software to record the PPT and attach the sound. They upload the recorded video to the network to make up for the absence of students. Soon they were more innovative attempts, gradually on the basis of the students watch video at home, listening to explain, in class, the teacher to main problem 
counselling, or who have difficulty in the process of doing experiments help [1]. Can be seen from this model the socalled flip classroom, create video is a teacher, students at home or outside to watch the video of the teacher's explanation, back to the face-to-face communication between teachers and students in the class and finish the homework such a teaching pattern [2]. The traditional teacher-centered education idea and the class collective teaching traditional teaching process change into studentcentered, autonomous learning, self evaluation, teachers to guide and help the teaching mode of [3].

This model has been eagerly watched by schools in recent years. Flipped classroom mode is not a single video online play mode, which is a kind of expansion mode based on the students' actual learning situation. In combination with advanced network and media technology, students are the center of the classroom, and the knowledge is taught through extracurricular activities. In the course, students and teachers interact and discuss the knowledge digestion, thus forming flipped classroom.

\section{BUILD AN ONLINE COLLABORATIVE LEARNING PLATFORM BASED ON FLIPPED CLASSROOM MODEL}

There are many courses in software design, more algorithms, more units, and more practicability. Traditional teaching students have a poor command of time in a fixed period of time, which can influence subsequent courses and practice. Aiming at this phenomenon, the application of flipped classroom model is a good solution. Through the construction of a complete online collaborative learning platform based on flipped classroom model to improve the teaching process and ensure the improvement of teaching effect. In online collaborative learning platform based on the pattern of flip classroom (as shown in figure 2), in the process of building the main body of learning through learning platform to complete the knowledge learning and internalizing, platform will students show teachers at the same time, teachers, and revised by thinking of teaching plan to build learning platform, to achieve good for the continual improvement of the student-centered teaching pattern.

\section{Subject of Learning}

In online learning, the platform's online courses are completely open to anyone, and the learner's identity is unrestricted. Anyone who passes through an Internet platform at any time and anywhere can learn synchronously or asynchronously. But the flipped classroom mode is retaught online, and the two parts are expanded offline, so the learning subject can be divided into two parts: the class

students and the other students online. The class students have a similar learning foundation for the study group of the teachers in the school, and they can complete the courses and related online teaching activities on the platform. At the same time, the teaching period arranged by the offline school can be discussed with the teacher in person, so as to improve the learning effect. Other students on the line have access to the platform through the Internet. They can participate in all the teaching sessions of online courses, but they cannot participate in the discussion and other activities of the school classroom.

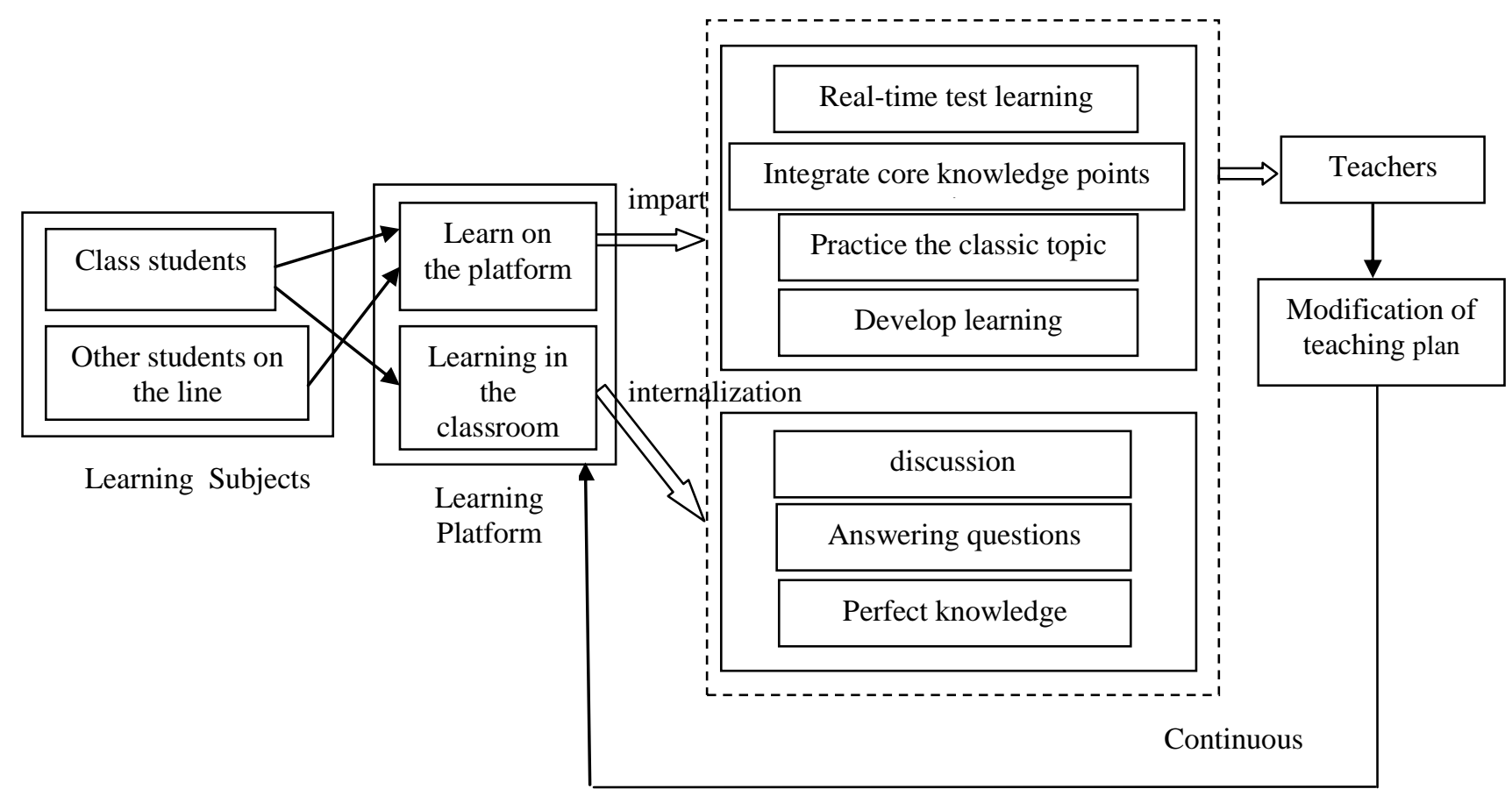

Figure 2. Construction of online collaborative learning platform based on flipped classroom mode 


\section{A. Learning Platform}

The subject of learning is to learn from the courses video, which is published to the teachers on the platform, and video can be watched over and over again, and the teacher can add to the exam node in video, and the students can perform the test results. Teacher video's release is organized according to the logical order of the core knowledge point system, while taking into account the deep expansion of the knowledge point. Students can choose their learning flexibly according to their actual situation. Traditional way of teaching is "classroom learning and after-school exercises," flip "extracurricular learning and classroom practice" class, in order to improve the correctness of the platform to watch video autonomous learning after class, the teacher will select the appropriate exercises for students to practice the teaching content, also can prepare some related discussion topic, fully mobilize students' interest in study, play to students' subjective initiative learning, lets the student unfold online discussion, or class to discuss the subject at school learning communication, problem sets of answering questions. Through online and offline cooperative learning, we have realized the teaching goal, improved the teaching effect, improved the students' knowledge system, and expanded the students' knowledge.

\section{B. Teacher s}

During the construction of online cooperative learning platform based on flipped classroom mode, teachers of the course have played an important role in the reform of the whole teaching mode even though the designer is the implementer.

First of all, teachers of software design courses teaching and research group should combine their own teaching practice to make new teaching content arrangement and replan for the students' actual situation. In the planning, there are not only individual curriculum planning, but also planning the relationship points between the software design courseses to promote the completion of overall teaching objectives.

Second, teachers will the commencement of the course content is decomposed into several teaching unit (chapter and section), each teaching unit according to the content of logic design into several micro unit (knowledge), will pick concise core knowledge, organizing teaching contents; Make mono-yuan teaching video.

Finally, through the "flip" classroom each link set in the feedback source, reflect on the problems in the teaching process, and timely adjust development learning, video resources platform, timely leak fill a vacancy, overturning personalized learning in the process of classroom teaching and teaching features and advantages into full play.

\section{Continuous Improvement}

Building a complete online collaborative learning platform based on flipped classroom mode is not a move of MOOC platform, and should be integrated into the student training program of the university. The teacher through the platform learning data feedback analysis, class answer analysis, reflection on the problems and solutions in the teaching. The factors that influence the teaching effect are various, including the state of the teacher, the organization of the language and the selection of knowledge in the video recording. The division and difficulty of the knowledge points in the exercise questions; Interest in learning; Knowledge points and so on. The teachers in the course group will actively improve the teaching plan after discussing the effect of classroom implementation, so that they can master the content of the course more deeply, so as to improve students' graduation effect. At the same time, the teaching and learning activities have also promoted teachers' information teaching ability.

\section{SUMMARY AND PROSPECT}

The online collaborative learning platform based on flipped classroom model provides students with more learning resources and a good platform. Except can reduce the difficulty of learning of the principle of course teachers also can form a complete set of course has to solve in the practice link to join the platform of software design algorithm is hard to understand well versed in classes. Select the appropriate school cooperation projects and place them in the learning platform for sharing learning. Through platform learning, students have ramped up the basic theoretical knowledge of software development, expanded the typical application capacity of software development, and strengthened the practice teaching process. It reduces the input of teacher resources and improves the teaching level of teachers. The construction of the platform is a continuous improvement process, and the reform of teaching mode is a process of constant research and exploration. Through the implementation effect to further summarize, reflect and improve, making flipped classroom a kind of normal teaching method is a question worth pondering over the next period.

\section{ACKNOWLEDGMENT}

Supported by Teaching reform research project of Xi'an technological university, (No. 16JGY24, 15JGY13) and Supported by research project on teaching reform of online open courses in shaanxi province, (No. 16MY19).

\section{REFERENCES}

[1] Baidu encyclopedia. Flipped classroom [DB/OL]. https://baike.baidu.com/item/ Flipped classroom /3381700

[2] 360 Library. "flipped classroom" teaching model [DB/OL]. http://www.360doc.com/content/13/125/21/14070959_332145620.sht $\mathrm{ml}$.

[3] Baidu encyclopedia. Micro-class [DB/OL]. http://baike.baidu.com/view/5982553.htm.

[4] Wang nuosi, li mengmeng. Research on multimedia teaching based on the theory of the mayer of multimedia.. China Management Informationization, vol. 1,2016, pp. 250-252.

[5] Zhang chi. Research on online course construction in the Internet era.Journal of Inner Mongolia university of finance and economics, vol. 6,2015 ,pp. $108-111$ 